\title{
Protrusão da radícula e métodos para superação de dormência de sementes de trigo
}

\author{
Radicle protrusion and methods for overcoming the wheat seed dormancy
}

\section{Andreia da Silva Almeida, Murilo Bortolotti, Letícia Ramon de Medeiros*, Geri Eduardo Meneghello, Luis Henrique Konzen e Lilian Madruga de Tunes}

\author{
Recebido em 11/05/2015 / Aceito em 10/06/2016
}

\section{RESUMO}

O objetivo deste trabalho foi estudar a eficiência de tratamentos de superação da dormência de sementes de Triticum aestivum L. Utilizaram-se quatro lotes de sementes (1, 2, 3 e 4), da cultivar BRS Guamirim, com teor de água de $12,5 \%$. Os tratamentos foram i) pré-esfriamento em temperatura de 5 a $10^{\circ} \mathrm{C}$; ii) présecagem em temperatura de 30 a $35^{\circ} \mathrm{C}$; iii) pré-secagem em temperatura de $50{ }^{\circ} \mathrm{C}$ submetidos por um período de exposição de $72 \mathrm{~h}$; iv) pré-secagem em temperatura de $50{ }^{\circ} \mathrm{C}$ submetidos por um período de exposição de 96 h; v) embebição do substrato do teste de germinação em solução de ácido giberélico e nitrato de potássio; e vi) a testemunha (sementes sem tratamento). O tempo de protrusão de radícula foi avaliado através de curvas de embebição. O delineamento experimental foi inteiramente casualizado no esquema fatorial $4 \mathrm{x}$ 6 (lotes de sementes $\mathrm{x}$ tratamentos para superação de dormência), com cinco repetições. Conclui-se que, os lotes 2 e 4 tiveram comportamentos semelhantes na curva de embebição, após um período de $16 \mathrm{~h}$ apresentando um teor de água de 43,2 e 40,7\%, respectivamente, devido ao maior grau de dormência dos lotes com 30 e $38 \%$ de germinação. O método térmico utilizando temperaturas de 30 a 35 e $50{ }^{\circ} \mathrm{C}$ $(72 \mathrm{~h})$ apresentam maior eficiência na superação da dormência de sementes de trigo sendo realizado em menor tempo quando comparado com o teste atualmente recomendado, pré-esfriamento.

PALAVRAS-CHAVE: Triticum aestivum L., germinação, viabilidade, curva de embebição.

\footnotetext{
ABSTRACT

The objective was to study the effectiveness of treatments to overcome dormancy of Triticum

Universidade Federal de Pelotas, Pelotas, RS, Brasil.

*Autor para correspondência <leticiardemedeiros@gmail.com>
}

aestivum L. seeds used four seed lots (1, 2, 3 and 4), BRS Guamirim with an initial moisture content of $12.5 \%$. The treatments were: pre-cooling temperature of 5 to $10{ }^{\circ} \mathrm{C}$; pre-drying temperature of 30 to $35^{\circ} \mathrm{C}$; pre-drying at $50{ }^{\circ} \mathrm{C}$ for a period of undergoing exposure 72 and $96 \mathrm{~h}$; imbibition of the germination test substrate using solution of gibberellic acid and potassium nitrate and untreated seeds (control). Time of radicle protrusion was assessed by soaking curve. The experimental design was completely randomized in a 4 x 6 factorial (seed lots $x$ treatments to overcome dormancy), with five repetitions. In conclusion, lots 2 and 4 had similar performance in the imbibition curve, having a water content of 43.2 and $40.7 \%$, respectively, after a $16 \mathrm{~h}$ period due to the higher degree of dormancy of lots with 30 and 38\% germination; method using the thermal temperature of 30 to 35 and $50{ }^{\circ} \mathrm{C}(72 \mathrm{~h})$ has increased efficiency in overcoming wheat seed dormancy being performed in less time when compared with test currently recommended precooling.

KEYWORDS: Triticum aestivum L., germination, viability, imbibitions curve.

A temperatura é um fator com influência significativa na expressão da dormência, durante o período de enchimento das sementes e após a maturidade. A dormência das sementes pode ser induzida pela baixa temperatura, durante o período de enchimento das sementes, sendo também efetiva para a superação da dormência após a maturidade (TUNES et al. 2009).

O processo de embebição ocorre, de forma geral, em três fases sendo que a fase inicial denominada de fase I é um fenômeno físico que ocorre entre a primeira e segunda hora de absorção de água, dependendo da espécie, na fase II de hidratação 
ocorrem atividades metabólicas e as reservas são convertidas em compostos mais simples para serem utilizados na germinação, já a fase III, devido ao aumento de expansão das células, observa-se novamente o aumento da quantidade água absorvida pelo embrião (BARROS \& PESKE 2006).

A superação da dormência está relacionada a fatores internos e externos à semente (CASTRO et al. 2004). Dormência em sementes de trigo foi considerada de grande importância para a tolerância a germinação de sementes na espiga (FRANCO et al. 2009).

Vários são os métodos para superar a dormência de sementes de gramíneas (POPININGIS 1985). Os principais são a ruptura da cariopse, o tratamento com nitrato de potássio, o emprego de tratamento térmico, o pré-esfriamento e tratamento com hormônios. Entre os reguladores de crescimento, as giberelinas (geralmente o ácido giberélico, $\mathrm{GA}_{3}$ ) são os compostos citados como os mais relacionados à superação de dormência (CARVALHO \& NAKAGAWA 2000).

Entre os métodos utilizados para superação de dormência de trigo é recomendado atualmente pelas Regras para Análise de Sementes (BRASIL 2009), o tratamento de pré-esfriamento. No entanto, este tratamento não foi eficiente em experimento realizado por FRANCO et al. (2009) devido as sementes utilizadas apresentarem alta concentração de ácido abscísico (ABA), inibidor da germinação.

Diante do exposto objetivou-se estudar a eficiência de diferentes tratamentos para superar a dormência de sementes de Triticum aestivum $\mathrm{L}$. e analisar a curva de embebição visando reduzir o tempo do teste de superação de dormência e deixá-lo mais eficiente.

A pesquisa foi realizada no Laboratório Didático e de Pesquisa em Sementes do Departamento de Fitotecnia, na Universidade Federal de Santa Maria e Universidade Federal de Pelotas, em Santa Maria e Pelotas, RS, Brasil, respectivamente. As sementes foram provenientes da empresa Roos, sediada no município de Não-Me-Toque no estado do Rio Grande do Sul, Brasil. O município situa-se na latitude de $28^{\circ} 27^{\prime} 33^{\prime \prime}$ Sul e longitude de 52॰49'15” Oeste estando a uma altitude de 514 metros.

Foram utilizados quatro lotes de sementes de trigo com a mesma procedência (ano agrícola e área de produção) de sementes de origem comercial, da cultivar BRS Guamirim que estavam com umidade inicial em $12,5 \%$, com todos os lotes com a teor de água semelhante.

Os lotes utilizados foram caracterizados através da determinação da curva de embebição (CE) das sementes, descrita a seguir: as CEs foram construídas com os valores da razão do peso final $(\mathrm{PF}) /$ peso inicial (PI) com amostras de sementes puras referentes aos quatro lotes de sementes, individualmente, utilizaram-se 25 sementes de cada lote, em quatro repetições; as sementes foram pesadas cinco vezes em intervalos regulares de $30 \mathrm{~min}$, totalizando $2 \mathrm{~h}$ e meia de imersão em água destilada, três pesagens com intervalos regulares de $1 \mathrm{~h}$ totalizando mais $2 \mathrm{~h}$ de imersão, finalmente mais uma com $3 \mathrm{~h}$ de intervalo, totalizando $12 \mathrm{~h}$ de imersão. O processo de imersão foi realizado em copos plásticos com volume de $20 \mathrm{~mL}$ de água destilada, metodologia adaptada conforme LOPES (1998).

As curvas foram graficamente representadas por dispersão de seus valores e com equação polinomial elevada ao grau que melhor adequou-se ao modelo de padrão trifásico (BEWLEY \& BLACK 1994) para o processo de absorção de água por sementes. A determinação do teor de água (\%) foi realizada através da diferença de peso utilizando-se a fórmula Peso Inicial x (100 - Umidade Inicial $)=$ Peso Final $x$ (100 - Umidade Final) (PESKE et al. 2006).

As sementes recém-colhidas apresentavam dormência e foram testados diferentes métodos de tratamento para a superação da dormência e assim avaliar a qualidade dos lotes. Algumas sementes dormentes devem passar por um período de amadurecimento pós-colheita devido à necessidade de ocorrência de complexas reações enzimáticas e bioquímicas, antes de elas germinarem (PESKE et al. 2006).

Para a superação de dormência das sementes em estudo utilizaram-se os seguintes tratamentos: i) pré-esfriamento em temperatura de 5 a $10{ }^{\circ} \mathrm{C}$; ii) pré-secagem em temperatura de 30 a $35^{\circ} \mathrm{C}$; iii) présecagem em temperatura de $50{ }^{\circ} \mathrm{C}$ submetidos por um período de exposição de $72 \mathrm{~h}$; iv) pré-secagem em temperatura de $50{ }^{\circ} \mathrm{C}$ submetidos por um período de exposição de 96 h; v) embebição do substrato do teste de germinação em solução de ácido giberélico e nitrato de potássio; vi) a testemunha (sementes sem tratamento).

O delineamento experimental foi inteiramente casualizado e as análises de variância foram efetuadas no esquema fatorial $4 \times 6$ (lotes $\times$ tratamentos para superação da dormência), com cinco repetições por 
tratamento.

Aavaliação de qualidade fisiológica foirealizada por meio do teste de germinação em que se utilizaram 100 sementes por lote, com quatro repetições, semeadas em rolos de papel toalha umedecidas com água destilada na proporção de 2,5 vezes, a massa do papel seco, para os tratamentos com pré-esfriamento e pré-secagem. Nos tratamentos com ácido giberélico e nitrato de potássio usaram-se o mesmo volume, no entanto, com adição de cada produto isolado para seu tratamento de superação. Os rolos de papel contendo as sementes foram colocados no interior de sacos plásticos e mantidos em germinador a $20^{\circ} \mathrm{C}$. A avaliação foi realizada aos oito dias após a semeadura (BRASIL 2009).

Utilizou-se a transformação em arco-seno $(\mathrm{x} / 100)^{0,5}$ para os dados em percentagem, para que os mesmos fossem normalmente distribuídos. As médias foram comparadas pelo teste de Tukey, utilizando o programa de análises estatístico Sisvar (FERREIRA 2000). Na Figura 1 e Tabela 1, as médias foram apresentadas sem transformação.

A Figura 1 reproduz a curva de embebição dos quatro lotes $(1,2,3$ e 4$)$ das sementes de trigo, a partir de uma média inicial de $12,5 \%$ de teor de água, até a protrusão da radícula. Pode-se observar que os lotes 2 e 4 tiveram comportamentos semelhantes na curva de embebição, apresentando um teor de água das sementes de 43 e $40 \%$, respectivamente, após um período de $16 \mathrm{~h}$.
Pesquisas têm sido conduzidas com o intuito de associar a qualidade fisiológica da semente com a sua velocidade de absorção de água; os resultados alcançados, contudo, não são conclusivos. Os lotes 2 e 4 (Tabela 1) mostraram-se os de maior grau de dormência e também nos quais as sementes absorveram uma percentagem de água mais elevada (Figura 1) principalmente nas primeiras horas durante o processo de embebição. Modo similar de absorção foi encontrado por ROCHA et al. (1984) ao avaliarem a capacidade de absorção de água de sementes de soja, evidenciaram que as de maior qualidade têm embebição mais lenta. BRUNO et al. (2001) também fazem menção a esta particularidade quando trabalharam com sementes de Mimosa aesalpinoefolia Benth.

Nas sementes não tratadas para a superação da dormência, os lotes 1 e 3 (Tabela 1) apresentaram menor intensidade de dormência inicial, provavelmente em virtude das condições ambientais durante o período de maturação das sementes, de acordo com BARROS \& PESKE (2006). A média de germinação indica que os lotes de sementes de trigo testados apresentam grau alto de dormência, havendo a necessidade de tratamento específico para a utilização dessas sementes logo depois da colheita visando a verificação da qualidade imediata do lote.

$\mathrm{Na}$ Tabela 1, pode-se observar que quando se optou pela temperatura de 5 a $10{ }^{\circ} \mathrm{C}$ para a superação de dormência, a germinação foi acima de $85 \%$, sendo

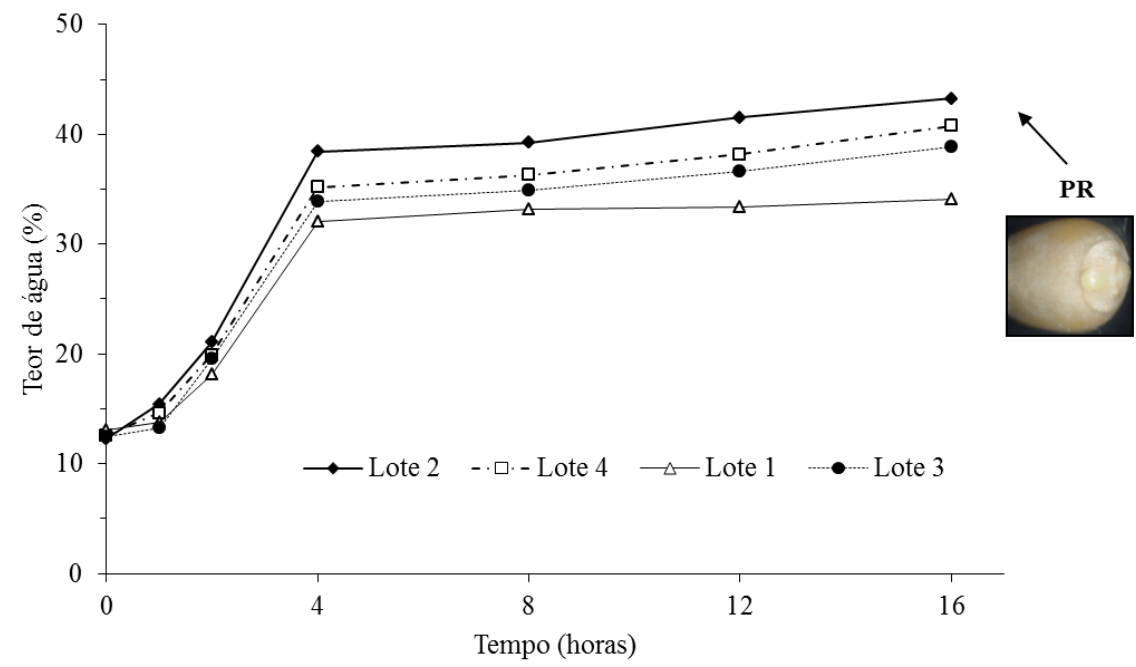

Figura 1 - Curva de hidratação de quatro lotes (1,2,3 e 4) de sementes de trigo cv. BRS Guamirim avaliadas em $0 ; 4 ; 8 ; 12$ e 16 horas de embebição. Pelotas, RS, 2014. *PR = protrusão da radícula.

Figure 1 - Four lots hydration curve (1, 2, 3 and 4) to wheat seed, cultivar BRS Guamirim evaluated at 0; 4; 8; 12 and 16 hours of imbibition. Pelotas, $R S, 2014$. ${ }^{*} R P=$ radicle protrusion. 
Tabela 1 - Médias de germinação (\%) de quatro lotes (1, 2, 3 e 4) de sementes de trigo cv. BRS Guamirim não tratadas (Test*) e tratadas $\left(\mathrm{F}^{*} ., \mathrm{T}^{*} ., \mathrm{T}^{*} .72 \mathrm{~h}, \mathrm{~T}^{*} .96 \mathrm{~h}, \mathrm{AG}_{3}{ }^{*}\right.$ e $\mathrm{KNO}_{3}{ }^{*}$ para a superação de dormência. Pelotas, RS, 2014.

Table 1 - Germination means (\%) of four lots (1, 2, 3 and 4) of untreated wheat seed, cultivar BRS Guamirim (Control $\left.{ }^{*}\right)$ and treated $\left(\mathrm{C}^{*} . \mathrm{T}^{*} . \mathrm{T} .72 \mathrm{~h}^{*}, \mathrm{T.96} \mathrm{h}^{*}, \mathrm{GA}_{3}{ }^{*}\right.$ and $\mathrm{KNO}_{3}{ }^{*}$ to overcome dormancy. Pelotas, RS, 2014.

\begin{tabular}{cccccccc}
\hline Lotes & Test. & $\begin{array}{c}\mathrm{F}^{*} . \\
\left(5 \mathrm{a} 10^{\circ} \mathrm{C}\right)\end{array}$ & $\begin{array}{c}\mathrm{T}^{*} . \\
\left(30 \mathrm{a} 35^{\circ} \mathrm{C}\right)\end{array}$ & $\begin{array}{c}\mathrm{T}^{*} .72 \mathrm{~h} \\
\left(50{ }^{\circ} \mathrm{C}\right)\end{array}$ & $\begin{array}{c}\mathrm{T}^{*} .96 \mathrm{~h} \\
\left(50{ }^{\circ} \mathrm{C}\right)\end{array}$ & $\mathrm{AG}_{3}^{*}$ & $\mathrm{KNO}_{3}^{*}$ \\
\hline 1 & $49 \mathrm{aD}$ & $88 \mathrm{aB}$ & $97 \mathrm{aA}$ & $95 \mathrm{aA}$ & $75 \mathrm{aC}$ & $90 \mathrm{aB}$ & $86 \mathrm{aB}$ \\
2 & $30 \mathrm{bC}$ & $86 \mathrm{aA}$ & $88 \mathrm{bA}$ & $86 \mathrm{bA}$ & $68 \mathrm{bB}$ & $79 \mathrm{bB}$ & $77 \mathrm{bB}$ \\
3 & $44 \mathrm{aC}$ & $87 \mathrm{aB}$ & $95 \mathrm{aA}$ & $95 \mathrm{aA}$ & $77 \mathrm{aB}$ & $83 \mathrm{bB}$ & $83 \mathrm{aB}$ \\
4 & $38 \mathrm{bD}$ & $85 \mathrm{aB}$ & $91 \mathrm{bA}$ & $90 \mathrm{bA}$ & $71 \mathrm{bC}$ & $82 \mathrm{bB}$ & $85 \mathrm{aB}$ \\
\hline
\end{tabular}

CV (\%) 5,17

* Test. (testemunha); F. 5 a $10{ }^{\circ} \mathrm{C}$ (frio); T. 30 a $35{ }^{\circ} \mathrm{C}$ (temperatura de 30 a $\left.35{ }^{\circ} \mathrm{C}\right) ;$ T. 72 horas $\left(50{ }^{\circ} \mathrm{C}\right) ;$ T. 96 horas $\left(50^{\circ} \mathrm{C}\right) ; \mathrm{AG}_{3} 200 \mathrm{mg} \mathrm{L}^{-1}$ (ácido giberélico) e $\mathrm{KNO}_{3}$ (nitrato de potássio). Médias seguidas das mesmas letras, maiúsculas nas linhas e minúsculas nas colunas, não diferem entre si pelo teste de Tukey a $5 \%$ de probabilidade.

$\mathrm{CV}=$ coeficiente de variação.

considerado uma valor próximo do mínimo exigido para os padrões de sementes de $80 \%$ (Instrução Normativa $\mathrm{n}^{\circ}$ 45, de 17 de setembro de 2013). Resultado semelhante foi encontrado em sementes de cevada após a colheita, independente da cultivar analisada (TUNES et al. 2009). De acordo com KISSMANN \& GROTH (2000), a variabilidade de respostas quanto ao requerimento de temperatura é um reflexo da adaptação das espécies ao ambiente de ocorrência, justificando elevada germinação do trigo em temperaturas mais baixas, pois esta espécie é cultivada em regiões frias do Brasil.

No entanto, em temperaturas mais altas de 30 a $35^{\circ} \mathrm{C}$ em câmara com circulação de ar por um período de sete dias (Tabela 1) foram observados os valores maiores para a germinação dos lotes de sementes analisados. Os resultados obtidos discordam da observação de DOUSSEAU et al. (2008) que atribuíram apenas ao aquecimento a aceleração do processo germinativo e não a um aumento na germinação, como ocorreu no presente trabalho. Segundo VARELA et al. (2005) em temperaturas mais altas, a velocidade de absorção de água e as atividades enzimáticas são intensificadas, o que permite maior expressão de seu potencial germinativo máximo.

Quanto ao tratamento com temperatura de $50{ }^{\circ} \mathrm{C}$ por um período de exposição das sementes de 72 horas (Tabela 1) TUNES et al. (2009) obtiveram resultados similares aos encontrados no tratamento com temperatura de $35{ }^{\circ} \mathrm{C}$. A ação imediata de tratamentos térmicos, na redução da taxa de dormência foi constatada em sementes de Brachiaria brizantha (MARTINS \& SILVA 2001), Brachiaria dictyoneura cv. Llanero (ALMEIDA \& SILVA 2001) e em sementes de cevada (TUNES et al. 2009).

As sementes atingiram o valor máximo de germinação quando foram tratadas com temperatura de $50{ }^{\circ} \mathrm{C}$ por um período de exposição de $72 \mathrm{~h} \mathrm{e}$ acima deste tempo (96 h) observou-se uma queda na germinação das mesmas (Tabela 1). Como o tratamento de $96 \mathrm{~h}$ o resultado apresentou germinação em todos os lotes abaixo de $80 \%$, valor abaixo dos padrões exigidos para comercialização de sementes de trigo. De acordo com VIEIRA et al. (1998), isso mostra que temperaturas altas associadas a longos períodos de exposição podem afetar a organização das membranas nos embriões, dessa forma, reduzindo a germinação. Já BRADBEER (1988) não acredita que o efeito de temperaturas elevadas removam algum bloqueio metabólico à germinação, no entanto, danos térmicos são caracterizados pela quebra de ligações peptídicas de proteínas que ocasionam a desnaturação de proteínas essenciais ao processo germinativo e consequentemente alterando reações enzimáticas (DOUSSEAU et al. 2008). Apesar de afetar a capacidade germinativa das sementes de trigo, o método foi eficiente para diferenciar os lotes em relação à sua qualidade.

O tratamento com ácido giberélico (AG3) estimulou significativamente a superação de 
dormência nos quatro lotes das sementes de trigo, com germinação acima de $80 \%$. BONOW (2008) indicou que a germinação de sementes de arroz pode ser promovida pela mudança hormonal e que o ácido giberélico $\left(\mathrm{AG}_{3}\right)$ que atua na promoção da germinação, isto sendo comprovado em espécies como o milho (Zea mays) e uvaia (Eugenia uvalha), de acordo com FERREIRA et al. (2002) e SCALON et al. (2004).

Para o tratamento com uso de $\mathrm{KNO}_{3}$ na superação da dormência (Tabela 1) somente o lote 2 apresentou diferença estatística significativa entre os testados, sendo classificado como de menor qualidade fisiológica. Este tipo de tratamento vem sendo pesquisado há muitos anos por vários autores (GAZZIERO et al. 1991, FRANK \& NABINGER 1996), os quais afirmam que o $\mathrm{KNO}_{3}$ é um agente eficiente na promoção da germinação de muitas sementes dormentes. A eficiência do tratamento com $\mathrm{KNO}_{3}$ como promotor da germinação é confirmada por FRANK \& NABINGER (1996) ao avaliarem a germinação de seis acessos de Paspalum notatum Flüegge, nos quais observaram um aumento na taxa de germinação de 65,9 para até $100 \%$. Por outro lado, em algumas espécies, como capim massambará (Sorghum halepense (L.) Pers.) a embebição do substrato com $\mathrm{KNO}_{3}(2 \%)$ parece não agir quando se trata de superação da dormência dessas sementes.

O uso de calor seco $\left(30\right.$ a $35^{\circ} \mathrm{C}$ e $50{ }^{\circ} \mathrm{C}$ por um período de exposição de $72 \mathrm{~h}$ ) na presente pesquisa permitiu obter maiores porcentuais de sementes germinadas que os tratamentos com temperatura baixa e método químico. Destacando este tratamento por ser mais eficiente em menos tempo quando comparado com o pré-resfriamento. Dentre os diversos fatores do ambiente físico, a temperatura tem sido considerada como um dos principais responsáveis pela percentagem final de germinação, por afetar especialmente a velocidade de absorção de água, a reativação das reações metabólicas, fundamentais aos processos de mobilização de reservas e a retomada de crescimento da radícula (DOUSSEAU et al. 2008).

Os lotes 2 e 4 tiveram comportamentos semelhantes na curva de embebição, apresentando um teor de água das sementes de 43,2 e 40,7\%, respectivamente, após um período de $16 \mathrm{~h}$. O método térmico utilizando temperatura de 30 a 35 e $50{ }^{\circ} \mathrm{C}$ $(72 \mathrm{~h})$ apresenta maior eficiência na superação da dormência de sementes de trigo sendo realizado em menor tempo quando comparado com o teste atualmente recomendado, pré-esfriamento. Além disso, faz-se necessária a realização de testes de vigor para relacionar com os testes de superação de dormência em sementes de trigo.

\section{REFERÊNCIAS}

ALMEIDA CR \& SILVA WR. 2001. Comportamento da dormência em sementes de braquiária submetidas às ações de tratamentos térmico e químico. Informativo ABRATES 11:25.

BARROS ACSA \& PESKE ST. 2006. Produção de Sementes. In: PESKE ST et al. Sementes: Fundamentos científicos e tecnológicos. 2.ed. Pelotas: UFPEL. p.470498.

BEWLEY JD \& BLACK M. 1994. Seeds: physiology of development and germination. Plenum Press, New York, USA. 445 p.

BONOW NR. 2008. Dormência e germinação de sementes de arroz. Seed News 7:42.

BRASIL. 2009. Ministério da Agricultura, Pecuária e Abastecimento. Regras para análise de sementes. Brasília: MAPA/ACS. 399p.

BRUNO RLA et al. 2001. Tratamentos pré-germinativos para superar a dormência de sementes de Mimosa caesalpino efolia Benth. Revista Brasileira de Sementes 23:136-143.

CARVALHO NM \& NAKAGAWA J. 2000. Sementes: ciência, tecnologia e produção. 4. ed. Jaboticabal: Funep. 588p.

CASTRO RD et al. 2004. Embebição e reativação do metabolismo. In: FERREIRA AG \& BORGHETTI F. (Orgs.). Germinação do básico ao aplicado. Porto Alegre: Artmed. p.149-162.

DOUSSEAU $\mathrm{S}$ et al. 2008. Germinação de sementes de tanchagem (Plantago tomentosa Lam.): influência da temperatura, luz e substrato. Ciência e Agrotecnologia 32:438-443.

FERREIRA DF. 2000. Análises estatísticas por meio do SISVAR para windows versão 4.0. In: 45 Reunião Anual Da Região Brasileira Da Sociedade Internacional De Biometria. São Carlos: UFSCAR. p.225-258.

FERREIRA $G$ et al. 2002. Uso de ácido giberélico em sementes de fruta-do-conde (Annona squamosa L.) visando à produção de mudas em diferentes embalagens. Revista Brasileira de Fruticultura 24:178-182.

FRANCO FA et al. 2009. Pré-esfriamento para superação da dormência de sementes de trigo colhidas na época da maturidade. Revista Brasileira de Sementes 31:245-252.

FRANK LB \& NABINGER C. 1996. Avaliação da germinação de seis acessos de Paspalum notatum Flügge, nativos do Rio Grande do Sul. Revista Brasileira de Sementes 18:102-107.

KISSMANN KG \& GROTH D. 2000. Plantas infestantes e nocivas. 2. ed. São Paulo: BASF. 726p.

LOPES JC et al. 1998. Tratamentos para superar a 
dormência em sementes de arroz (Oryza sativa L.). Revista Brasileira de Sementes 20:87-92.

MARTINS L \& SILVA WR. 2001. Comportamento da dormência em sementes de braquiária submetidas a tratamentos térmicos e químicos. Pesquisa Agropecuária Brasileira 36: 997-1003.

PESKE ST et al. 2006. Sementes: fundamentos científicos e tecnológicos. 2 ed. Pelotas: UFPel. 470p.

POPININGIS F. 1985. Fisiologia de sementes. Brasília: Agriplan. 285p.

SCALON SPQ et al. 2004. Armazenamento e germinação de sementes de uvaia Eugenia uvalha Cambess. Ciência e Agrotecnologia 28:1228-1234.

TUNES LM et al. 2009. Tratamentos para superação da dormência de sementes de cevada. Scientia Agraria 10:1521.

VARELA VP et al. 2005. Influência da temperatura e do substrato na germinação de sementes de itaubarana (Acosmiumnitens (Vog.) Yakovlev) - Leguminosae, Caesalpinoideae. Acta Amazônica 35:35-39.

VIEIRA HD et al. 1998. Efeito de diferentes temperaturas sobre a dormência fisiológica de sementes de braquiarão (Brachiaria brizantha Hochst. ex A. Rich). Revista Brasileira de Sementes 20:84-88. 